DO I: $10.7242 / 2658-705 X / 2020.2 .7$

УДК 575.174.015.3

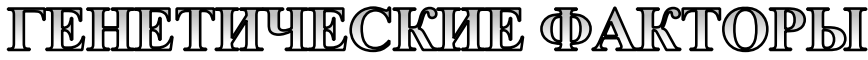

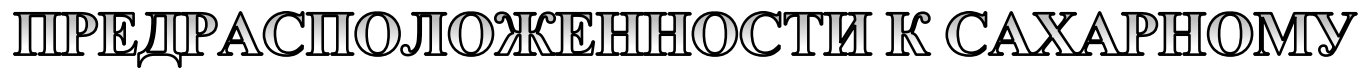

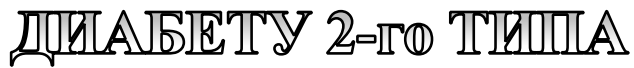

А.С. Ширинкина, Пермский федеральный исследовательский центр УрО РАН

А.Ю. Максимов, Институт экологии и генетики микроорганизмов УрО РАН

Представлен обзор исследований по генетике сахарного диабета 2 го типа. Описаны гены, связанные с развитием заболевания, имеющие диагностическое значение, которые могут быть идентифицированы на основании молекулярно-генетических исследований. Обсуждаются влияние факторов окружающей среды и образа жизни на развитие диабета. Представлены обзорные данные о направлении в диагностике сахарного диабета (СД) - предиктивной медицине.

Ключевые слова: сахарный диабет 2-го типа, полиморфизм генов, однонуклеотидный полиморфизм, предиктивная медицина.

\section{Введение}

Сахарный диабет (СД) - это серьезное хроническое заболевание, которое развивается, когда поджелудочная железа не вырабатывает достаточно инсулина (гормона, регулирующего метаболизм глюкозы и её содержание в крови) или когда организм не может эффективно использовать выработанный им инсулин. Как серьезная проблема общественного здравоохранения, которую планируется решать на глобальном уровне, диабет является одним из четырех приоритетных неинфекционных заболеваний (НИЗ) $[10$, с. 9]. СД по темпам роста распространенности опережает все остальные неинфекционные заболевания. Сахарный диабет стал международной проблемой, поскольку на протяжении жизни он развивается и диагностируется как минимум у 1 из 10 человек, и распространенность его во всем мире во многих этниче- ских группах и среди людей с разным социально-экономическим уровнем неуклонно нарастает. В 2001 г. было зарегистрировано 170 миллионов человек с сахарным диабетом 2-го типа (СД2). К 2015 г. это число составило 300 миллионов [16, с. 16]. Сахарный диабет приводит не просто к потере здоровья, к формированию множества его осложнений, сокращению качества и продолжительности жизни, но и к огромным финансовым тратам - закупкам медикаментов, постоянному контролю различных анализов, частым госпитализациям и социальным пособиям по инвалидности, которые ложатся бременем на государственный и местный бюджеты или кошелек самого пациента. Сахарный диабет входит в топ-десятку самых дорогих массовых заболеваний [5, с. 93].

Распространенность сахарного диабета стремительно растет во всем мире и, по данным Международной диабетиче-

* Работа выполнена в рамках государственного задания; номер государственной регистрации темы AАAА-A19-119051390040-5. 
ской федерации, на сегодняшний день составляет более 425 млн человек. На конец 2018 года в России насчитывалось 4,58 млн больных диабетом, 92,6\% которых (4,24 млн человек) страдают сахарным диабетом 2-го типа [2]. За период с 2000 по 2018 г. число больных СД2 в нашей стране выросло более чем в 2 раза. Всероссийское эпидемиологическое исследование NATION выявило диабетическую гипергликемию у $5,4 \%$ участников исследования в возрасте 20-79 лет, что увеличивает общее число пациентов до 8 млн человек [2, с. 11].

Понятие «ген» (от греч. genos - род, рождение, происхождение) в генетике является фундаментальным. Этим термином обозначают неделимую в функциональном отношении единицу генетической информации. Важность этого понятия определяется тем, что в геноме организма гены формируют генетическую систему управления, на основе которой развиваются элементарные признаки (в форме огромного разнообразия белковых молекул), а затем гуморальные и нервные механизмы регуляции, физиологические и поведенческие функции целостного организма. Генетическая информация, закодированная в виде последовательности нуклеотидов в ДНК, является составной частью наследственной информации. [3, с. 143].

Выраженные популяционные, этнические и, главное, индивидуальные особенности геномов как в их смысловой части (экзонов генов), так и в некодирующих последовательностях, обусловлены мутациями, приводящими к генетическому полиморфизму (ГП). Генетическая суть аллелизма сводится к тому, что множественные аллели несут различия, влияющие на функцию белка, а, следовательно, изменяющие фенотип. Из множественного аллелизма возникло представление об аллельном полиморфизме. Наличие в популяции множественных аллелей одного локуса называется генетическим полиморфизмом. Если аллели одного локуса отличаются одним нуклеотидом, то такое различие называются однонуклео- тидным полиморфизмом (ОНП). ОНП это наиболее общий источник вариаций между людьми. Именно ОНП придает уникальную индивидуальность, к пониманию сути, которой наука приближается только сейчас [18, с. 126].

Ряд заболеваний может передаваться по наследству, были обнаружены гены и их белковые продукты, которые отвечают за развитие различных заболеваний. В лабораторной практике их называют генетическими маркёрами». Изучение таких маркёров дает возможность выделить группы различного риска развития заболеваний, в частности диабета. Это является важным этапом его диагностики, поскольку в сочетании с традиционными методами (определение глюкозы, гликированного гемоглобина, гормонов, выявление аутоантител) приводит к обнаружению заболевания еще до проявления его выраженных клинических симптомов и помогает разработке профилактических мер.

Одна из задач медицинской генетики выявление генетических факторов риска мультифакториальных заболеваний $[11$, с. 5]. Появляется возможность своевременно выявлять мутации и полиморфизмы, ассоциированные с заболеваниями. Обнаружение мутаций, связанных с моногенными болезнями, используют в целях их диагностики при наличии соответствующих клинических признаков.

Исследование генных полиморфизмов проводят с целью выявления наследственных факторов предрасположенности к мультифакторным заболеваниям и своевременного устранения вредоносных факторов внешней среды. Таким образом, своевременное выявление генных полиморфизмов - основа предиктивной медицины. Эти знания позволяют врачу дать индивидуальные рекомендации пациенту для предотвращения у него развития одного из мультифакторных заболеваний [13].

Изменчивость определяется существованием различных состояний генов или аллелей. При этом нормальная изменчивость связана с присутствием у разных индивидуумов нормальных вариантов 
гена, а патологическая изменчивость - с наличием множества мутантных аллелей или мутаций $[11$, с. 5].

\section{Генетическая предрасположенность к сахарному диабету}

Наследственность сахарного диабета 2-го типа оценивается в 30-70\% (3). Основными патологическими причинами диабета 2-го типа являются резистентность к инсулину, снижение его секреции по сравнению с гипергликемией, дисфункция $\beta$-клеток поджелудочной железы (PBC), нарушение транспорта глюкозы в почках и эффект инкретина. Эти функциональные нарушения возникают в результате взаимодействия генетических и экологических факторов риска [28, с. 166].

Метаболические расстройства, наблюдаемые при СД, в первую очередь отражают степень абсолютного или относительного дефицита инсулина. Поскольку инсулин является основным анаболическим гормоном, его недостаток приводит к снижению способности организма пополнять энергетические резервы из-за недостаточного накопления потребляемой пищи.

На СД 2-го типа приходится около 90\% всех случаев диабета; в основном это происходит из-за неэффективного использования организмом инсулина и неспособности $\beta$-клеток поджелудочной железы компенсировать повышенную потребность в инсулине, приводящую к неконтролируемому гомеостазу глюкозы. Со временем плохой гликемический контроль затрагивает несколько районов тела, особенно кровеносные сосуды и нервы, способствуя развитию и прогрессированию невропатий, микро- и макрососудистых осложнений и преждевременной смерти [26, с. 1$]$.

Успешное секвенирование генома человека ознаменовало новую эру персонализированной медицины, в которой вариации генома будут использоваться для прогнозирования воздействия конкретных терапевтических вмешательств, ведущих к оптимальному лечению заболевания у данного человека. Однако мно- гие из наших наиболее распространенных хронических заболеваний являются полигенными, включая диабет и сердечно-сосудистые заболевания [27, с. 43].

Особенностью сахарного диабета 2-го типа является возможность его предотвращения путем профилактики. Ещё одним отличием развития сахарного диабета 2-го типа является то, что заболевание не начинается в момент выявления значительной гипергликемии, а развивается постепенно.

\section{Полиморфизм генов как основа предиктивной медицины. Точечный нуклеотидный полиморфизм}

Предполагается, что около половины всех значимых точечных нуклеотидных полиморфизмов (SNP) приходятся на смысловую (экспрессирующуюся) часть генома. Именно эти замены нередко представляют собой аллельные варианты генов, ассоциированных с различными мультифакторными заболеваниями (МФЗ). Им принадлежит основная роль в ГП человека. Полиморфизмы, затрагивающие смысловые части генов, нередко приводят к замене аминокислот и появлению белков с измененными или новыми функциональными свойствами. Особенно существенное влияние на активность экспрессии генов могут иметь замены или повторы нуклеотидов в регуляторных (промоторных) областях генов. Наследуемые полиморфные изменения генов играют решающую роль в определении уникального биохимического профиля каждого человека, в его наследственной предрасположенности к различным МФЗ [4, с. 78$]$.

Точечные нуклеотидные полиморфизмы (SNP), обусловленные заменой одного нуклеотида на другой, составляют примерно 90\% всех изменений. В геноме человека SNP появляются с частотой 1 на каждые 800-1200 оснований. SNP возникают как в кодирующей, так и в некодирующей части генома. Они эволюционно стабильны, не меняются от поколения к поколению и пе- 
редаются по наследству. В связи с этим важной задачей геномных исследований является создание карт SNP по протяженности всего генома человека [19, с. 87].

Персонализированная медицина - это принципиально новое профилактическое направление в здравоохранении, основанное на инновационных геномных, постгеномных, гормонально-метаболических и клеточных технологиях, которые позволяют прогнозировать и нивелировать риск развития социально значимых и наследственных заболеваний как для конкретного человека, так и для целых этнических групп. Одним из важнейших направлений персонализированной медицины является подбор индивидуальной терапии, которая будет действовать именно у данного пациента. Таким образом, благодаря развитию персонализированной медицины, эндокринологи могут правильно диагностировать сахарный диабет, грамотно оценить риски развития осложнений, а также подобрать эффективную лекарственную терапию для каждого конкретного больного [12, с. 6].

Сахарный диабет 2-го типа является гетерогенным заболеванием, развивающимся в результате комбинации генетических и приобретенных факторов. Основу предрасположенности к СД2 даёт персональный геном человека, который может содержать аллели генов, готовые под воздействием факторов окружающей среды вызывать развитие заболевания [22, с. 1].

Концепция персонализированной медицины в области диабета предполагает индивидуальное прогнозирование риска его развития, поиск наиболее эффективного и максимально безопасного метода профилактики и лечения заболевания для каждого отдельного пациента [12, с. 5].

В отличие от СД1 при СД2 прослеживается четкая генетическая детерминированность наследования. Так, риск развития СД2 составляет до $40 \%$, если болен один из родителей, до $70 \%$ - если больны оба родителя. [7, с. 11]. Молекулярные механизмы развития инсулинорезистентности (ключевого звена в развитии СД2) многообразны и сцеплены с много- уровневыми поломками на пути передачи сигнала от рецептора инсулина на внутриклеточные структуры. Различные уровни поломки передачи внутриклеточного сигнала определяют гетерогенность самой инсулинорезистентности и, соответственно, необходимость поиска индивидуальных методов воздействия на нее. Именно гетерогенностью инсулинорезистентности объясняется частая неэффективность лечения больных СД2 традиционными препаратами. Поэтому необходимо детальное изучение внутриклеточных механизмов развития инсулинорезистентности для поиска новых лекарственных препаратов, адресно воздействующих на тот или иной механизм патогенеза СД-2, для повышения эффективности лечения пациентов [12, с. 7].

\section{Анализ маркеров генетического полиморфизма, обусловливающих предрасположенность к СД2}

Добавление к существующим тестсистемам новых генетических маркеров позволит увеличить вероятность обнаружения наследственной предрасположенности к сахарному диабету и обеспечить реализацию мероприятий, направленных на его профилактику и раннее выявление групп генетического риска.

Ген АВСС8 кодирует рецептор к сульфонилмочевине, который представляет собой белок, относящийся к семейству АТФ-связывающих кассетных транспортеров, который может быть ответственен за развитие СД 2-го типа. [25, с. 11]. Было установлено, что мутации $\mathrm{rs} 757110 \mathrm{C} / \mathrm{T}$ этого гена могут быть связаны с гиперинсулинемией - состоянием, при котором уровень инсулина в крови превышает нормальное значение. Поджелудочная железа в течение длительного периода вырабатывает много инсулина, это приводит к ее изнашиванию и нарушению нормального функционирования. Часто из-за гиперинсулинемии развивается метаболический синдром, который может быть предвестником сахарного диабета [8, с. 46]. 
Ген адипонектина ADIPOQ кодирует белок адипонектин, который активно участвует во многих обменных процессах организма, включая углеводный обмен. Адипонектин поддерживает уровень глюкозы в скелетных мышцах и печени путем повышения чувствительности тканей к инсулину [6]. Исследование полиморфного локуса G276T гена ADIPOQ выявило ассоциацию гетерозиготного генотипа и аллеля 276T с повышенным риском СД2. При наличии гетерозиготного генотипа G276T риск развития СД2 увеличивается в 1,79 раза, а аллеля 276Т - в 1,68 раза [14, с. 221].

Некоторые варианты ADIPOR2 показали ассоциацию с инсулинорезистентностью, снижением концентрации триглицеридов и уменьшением уровня окисления липидов. В финской популяции полиморфный маркер G795A (rs16928751) гена ADIPOR2 был связан с риском развития сердечно-сосудистых заболеваний у лиц с нарушенной толерантностью к глюкозе. Однако следует отметить, что исследования ассоциации с СД2 в нескольких европейских популяциях показали противоречивые результаты. [24, с. 7].

Также с риском развития СД 2-го типа связывают HHEX - ген. Ген HHEX (hematopoietically expressed homeobox) rs1111875 G/A кодирует фактор транскрипции, отвечая за дифференцировку ряда органов: структур мозга, печени, поджелудочной железы, щитовидной железы и др. У взрослых селективно экспрессируется в дельтаклетках поджелудочной железы, ответственных за секрецию соматостатина. Сниженный уровень соматостатина может вызвать нарушения функционирования паракринной системы и, как следствие, снижение выброса инсулина бета-клетками поджелудочной железы. Носители определенных полиморфных вариантов гена НHЕХ имеют более высокие уровни глюкагона и глюкозы. В то же время данный фактор связывают с риском развития СД 2-го типа и полагают, что наличие определенных полиморфизмов нарушает как чувствительность к инсулину, так и его секрецию вне зависимости от уровня глюкозы [9, с. 87].

Продукт гена KCNJ11 - белок Kir6.2, который участвует в образовании АТФзависимого канала, регулирующего поток ионов калия через клеточную мембрану, связывая метаболизм глюкозы с электрическим потенциалом $\beta$-клетки. Закрытие канала необходимо для секреции глюкозостимулированного инсулина $\beta$-клетками поджелудочной железы. Открытие АТФ-зависимого канала ингибирует секрецию инсулина. Мутации в гене KCNJ11 приводят к изменениям в структуре белка Kir6.2 и нарушениям функционирования канала, активность которого повышается, способствуя развитию инсулинорезистентности. Исследования последних лет показали, что в ряде популяций выявлена ассоциация полиморфного маркера rs5219 гена KCNJ11 с риском развития СД 2-го типа [17, с. 62].

Ген KCNQ1 (potassium voltage-gated channel KQT-like subfamily, member 1) расположен в локусе $11 \mathrm{p} 15.5$, кодирует белок, который играет ключевую роль в реполяризации сердечного потенциала действия, а также в транспортировке воды и соли в эпителиальных тканях. Продукт гена KCNQ1 экспрессируется в островках Лангерганса и участвует в регуляции секреции инсулина $\beta$-клетками поджелудочной железы. Установлена связь полиморфизма rs2237892, расположенного в 15-м интроне гена KCNQ1, с повышенным риском развития СД2 [20, с. 75]

Результаты молекулярно-генетических исследований показали связь между полиморфными вариантами генов рецепторов мелатонина и развитием СД2. Два варианта однонуклеотидного полиморфизма гена MT2 (MTNR1B): rs1387153 и rs 10830963 ассоциированы с гликемией натощак, секрецией инсулина и СД2 в европейских популяциях. Установлено, что наличие аллеля $T$ локуса rs1387153 ассоциировано с уровнем глюкозы плазмы натощак $(\beta=0,06$ ммоль/л) и риском развития гипергликемии или СД2. 
В норме уровень инсулина наиболее низкий ночью, когда повышается уровень мелатонина. Изменение циркадного ритма может способствовать и нарушению секреции инсулина [15, с. 12].

Ген PPARG кодирует рецептор PPAR $\gamma$, который вовлечен в контроль экспрессии генов, участвующих в регуляции обмена жирных кислот. Мутации в «рабочих» участках гена вызывают повышение концентрации глюкозы в крови, приводят к избыточной массе тела и развитию диабета. Мутация в гене PPARG rs1801282 C/G вызывает изменение рецептора PPAR 2 , что проявляется нарушением метаболизма жирных кислот с развитием инсулинорезистентности, дислипидемией, гипертонией, увеличением массы тела и нарушением гомеостаза глюкозы [6, с. 20].

Ионы цинка являются жизненно необходимыми для обеспечения нормального хранения и секреции инсулина бета-клетками поджелудочной железы. В секреторных гранулах инсулин, соединяясь с ионами цинка, образует кристаллические гексамерные агрегаты. Ген SLC30A8 кодирует трансмембранный белок-транспортер ионов цинка типа 8 (ZnT-8). ZnT-8 выполняет функцию канала, через который ионы Zn2+ поступают секреторные везикулы. По данным метаанализа, включившего 46 исследований, однонуклеотидный полиморфизм rs13266634 гена SLC30A8 ассоциирован с риском развития СД 2-го типа. Данная закономерность выявлена для африканской, европейской и в азиатской популяций. Набор веса во время беременности может модифицировать экспрессию SLC30A8 и способствовать развитию СД 2-го типа [9, с. 88].

Продукт гена TCF7L2 C/T может нарушать способность панкреатических островков продуцировать инсулин в ответ на стимуляцию инсулинотропным интестинальным гормоном ГПП-1 или глюкозой. Аллель локуса rs7903146 ассоциирован с риском развития СД2, нарушенной секрецией инсулина, действием инкретинов и усиленной продукцией глюкозы печенью [1, с. 120].
Ген разобщающего белка 2, UCP2 (uncoupling protein 2), экспрессируемого многими видами тканей, препятствует выработке инсулина клетками поджелудочной железы. Белок UCP2 относится к семейству термогенинов, транспортеров внутренней мембраны митохондрий, осуществляющих перенос протонов через мембрану, уменьшающих градиент протонов и разобщающих процессы окисления и фосфорилирования. При потреблении продуктов с высоким содержанием жира экспрессия UCP2 в белых адипоцитах увеличивается, что указывает на влияние UCP2 на скорость метаболизма и, возможно, на устойчивость к ожирению. Генетические изменения в гене UCP2 воздействуют на патогенез ожирения и СД 2. В частности, мутация rs659366 G/A гена UCP2 нарушает нормальную выработку инсулина клетками поджелудочной железы [21].

Ген UCP2 (11q13), играет одну из ключевых ролей в терморегуляции, связан с процессами аккумуляции жиров и рассеиванием энергии в виде тепла. В гене UCP2 наиболее изучен Ala55Val полиморфизм в 4-м экзоне, с частотой встречаемости аллели Val от 40 до 60\% в мировых популяциях. Аллель Val acсоциирована с повышенным риском развития сахарного диабета 2 и ожирения [23, с. 36].

Мутация rs1800849 C/T гена UCP3, кодирующего разобщающий белок 3 , замедляет метаболизм жирных кислот, что приводит к нарушению углеводного и жирового обмена. Замедленный метаболизм жирных кислот является важным предшественником инсулинорезистентности и определяет количество жира, хранящегося в виде внутримышечных липидов, которые отрицательно коррелируют с чувствительностью к инсулину [23; с. 36].

Ген WSF1 - ген вольфрамина кодирует трансмембранный белок мембран эндоплазматического ретикулума. Он участвует в регуляции гомеостаза ионов кальция. Нарушения в структуре белка могут приводить к изменению кальциевого гомеостаза, что, в свою 
очередь, нарушает секрецию инсулина бета-клетками. Полиморфный маркер rs1801214 гена WSF1 ассоциирован с развитием СД 2-го типа. Подтверждена также связь между данным полиморфизмом и развитием СД у американцев африканского происхождения [7, с. 14].

\section{Заключение}

Сахарный диабет - быстро распространяющееся заболевание, являющееся одной из важнейших проблем здравоохранения. Согласно прогнозам ВО3, количество пациентов с таким диагнозом будет неуклонно увеличиваться.

Известно большое количество полиморфизмов, ассоциированных с развитием СД2, распространенных также и в русской популяции. Всё это свидетельствует о важности изучения генетических факторов, способствующих развитию заболевания. Идентификация генетических маркеров риска СД2 позволяет лучше понять основной патологический механизм его развития и, в соответствии с этим, использовать полученные данные для профилактики СД2 у здоровых людей или выбрать оптимальную индивидуальную стратегию терапии этого заболевания.

\section{Библиографический список}

1. Авзалетдинова Д.Ш., Шарипова Л.Ф., Кочетова О.В., Моругова Т.В., Эрдман В.В., Сомова Р.Ш., Myстафина O.E. Анализ ассоциаций полиморфного маркера rs7903146 гена TCF7L2 с сахарным диабетом 2-го типа в татарской этнической группе, проживающей в Башкортостане // Сахарный диабет. - 2016. - № 2. - С. 119-123.

2. Азарова Ю.Э., Клёсова Е.Ю., Сакали С.Ю., и др. Вклад полиморфизма rs11927381 гена IGF2BP2 в патогенез сахарного диабета 2-го типа. // Научные результаты биомедицинских исследований. 2020. - № 1. - C. 9-19.

3. Андреев В.П. Ген: структурно-функциональная организация единиц генетической информации. // Журнал Гродненского государственного медицинского университета. - 2007. - № 4. - С. $143-152$.

4. Баранов В.С. Геномика на пути к предиктивной медицине // Acta naturae. - 2009. - № 3. - C.77-88.

5. Болдырева Л. В. Сахарный диабет и новые взгляды на проблему // Символ науки - 2016. - № 4. C. 93-95.

6. Бондарь И.А., Филипенко М.Л., Шабельникова О.Ю., Соколова Е.А., Ассоциация полиморфных маркеров rs7903146 гена TCF7L2 и rs1801282 гена PPARG (Pro12Ala) с сахарным диабетом 2-го типа в Новосибирской области // Сахарный диабет. - 2013. - № 4. - С. 17-22.

7. Бондарь И.А., Шабельникова О.Ю. Генетические основы сахарного диабета 2-го типа // Сахарный диабет. - 2013. - № 4. - С. 11-16.

8. Бондарь И.А., Филипенко М.Л., Шабельникова О.Ю., Соколова Е.А., Отсутствие ассоциации полиморфных локусов rs5219 гена KCNJ11 и rs757110 гена АВСС8 с долгосрочным ответом на терапию препаратами сульфонилмочевины в Новосибирской области // Сахарный диабет. - 2015. № 1. - С. 42-47.

9. Буряковская А.А., Исаева А.С. Сахарный диабет: роль генетических факторов в развитии заболевания // Международный эндокринологический журнал. - 2017. - № 1. - С. 81-96.

10. Всемирная организация здравоохранения. Глобальный доклад по диабету. $-2016 .-88$ с.

11. Горбунова В. Н. Медицинская генетика. Учебник для студентов медицинских вузов и слушателей последипломного образования. - М.: Изд-во «Фолиант», $-2015 .-357$ с.

12. Дедов И.И., Шестакова М.В. Персонализированная терапия сахарного диабета: путь от болезни к больному // Терапевтический архив. - 2014. - № 10. - С. 4-8.

13. Инвитро Генетические исследования [Электронный pecypc] URL: https://www.invitro.ru/library/labdiagnostika/17237/ (дата обращения: 23.10.2019).

14. Исакова Ж.Т., Талайбекова Э.Т., Жыргалбекова Б.Ж., Миррахимов Э.М., Алдашева Н.М., Алдашев A.A. Межгенные взаимодействия и вклад полиморфных локусов генов KCNJ11, ADIPOQ, оментина, лептина, TCF7L2 и PPARg в развитие сахарного диабета 2-го типа в кыргызской популяции: предварительные результаты исследования по типу случай-контроль с использованием MDR-анализа // Проблемы эндокринологии. - 2018. - Т. 64. - № 4. - С. $216-225$.

15. Коненков В.И., Климонтов В.В., Мичурина С.В., Прудникова М.А., Ищенко И.Ю. Мелатонин при сахарном диабете: от патофизиологии к перспективам лечения // Сахарный диабет. - 2013. - № 2. C. $11-16$.

16. Кураева Т.Л., Дубинина И.А. Клиника и дифференциальная диагностика сахарного диабета 2-го типа в детском возрасте // Сахарный диабет. - 2009. - №3. - С. 16-21. 
17. Лапик И.А., Гаппарова К.М., Шарафетдинов Х.Х., Сорокина Е.Ю., Сениова Т.Б., Плотникова О.А., Чехонина Ю.Г. Оценка эффективности персонализированной терапии больных ожирением и сахарным диабетом 2-го типа, назначенной на основе изучения полиморфизма rs5219 гена KCNJ11 // Вопросы питания. - 2016. - № 2. - С. 61-66.

18. Майборода A.A. Генетический полиморфизм: теория и практика // Сибирский медицинский журнал. 2014. - № 8. - C. 125-129.

19. Мохосоев И.М., Терентьев А.А. Генетический полиморфизм и предрасположенность к многофакторным заболеваниям // Успехи современного естествознания. - 2005. - № 12 - С. 87-87.

20. Орлов П.С., Иваномук Д.Е., Михайлова С.В., Максимов В.Н., Воевода М.И. Исследование ассоциаций новых генетических маркеров сахарного диабета 2-го типа на Западно-Сибирской популяции европеоидов // Сибирский научный медицинский журнал. - 2015. - № 2. - С. 74-79.

21. Постгеномные и нанотехнологические инновации. UCP2 (ген разобщающего белка 2) [Электронный ресурc] URL: http://xn--h1aaoah.xn--p1ai/information/genes-information/159.html (дата обращения: 23.10.2019).

22. Сорокина Ю.А. Однонуклеотидный полиморфизм гена репарации ДНК - 8-оксогуанидин-ДНКгликозилазы: от онкологии к сахарному диабету 2-го типа (обзор литературы) // Journal of Siberian Medical Sciences. - 2015. - №. 1. - C. 1-10.

23. Тарковская И.В., Глотов О.С., Иващенко Т.Э., Баранов В.С. Особенности полиморфизма генов энергетического обмена PGC-1, семейств PPAR и UCP в двух возрастных г. Санкт-Петербурга // Экологическая генетика - 2011. - № 4. - С. 35-42.

24. Ходырев Д.С., Никитин А.Г., Бровкин А.Н., Лаврикова Е.Ю., Лебедева Н.О., Викулова О.К., Шамхалова М.Ш., Шестакова М.В., Носиков В.В., Аверьянов А.В. Анализ ассоциации полиморфных маркеров генов ADIPOQ, ADIPOR1 и ADIPOR2 с сахарным диабетом 2-го типа // Сахарный диабет. - 2015. - № 2. - С. 5-11.

25. Шорохова П.Б., Загородникова К.А., Баранов В.Л., Ворохобина Н.В. Значение полиморфизма в генах KCNJ11, ABCC8 и TCF7L2 для ответа на терапию основными группами пероральных сахароснижающих препаратов // Фармакогенетика и фармакогеномика. - 2018. - № 1. - С. 9-14.

26. Gaia Chiara Mannino, F.Andreozzi, G.Sesti, Pharmacogenetics of Type 2 Diabetes Mellitus, the Route Toward Tailored Medicine // Diabetes Metab. Res. Rev. - 2019. - № 3. - P. 1-20.

27. Newgard C.B. Metabolomics and Metabolic Diseases: Where Do We Stand? // Cell. Metab. - 2017. - № 1. P. 43-56.

28. Reza H., Meybodi A., Hasanzad M., Larijani B., Path to Personalized Medicine for Type 2 Diabetes Mellitus: Reality and Hope // Acta Med. - 2017. - № 3. - P. 166-174. 


\title{
GENETIC PREDISPOSITION FACTORS FOR TYPE 2 DIABETES
}

\author{
A.S. Shirinkina ${ }^{1}$, A.Yu. Maksimov ${ }^{2}$ \\ ${ }^{1}$ Perm Federal Research Center UB RAS \\ ${ }^{2}$ Institute of Ecology and Genetics of Microorganisms UB RAS
}

This article provides an overview of studies on the genetics of type 2 diabetes. Genes associated with the development of the disease are described, which can be identified on the basis of molecular genetic studies. The role of environmental factors and lifestyle in the development of diabetes is also discussed. The overview data on the direction in the diagnosis of diabetes mellitus (DM) in terms of predictive medicine.

Keywords: diabetes mellitus, gene polymorphism, single nucleotide polymorphism, predictive medicine.

\section{Сведения об авторах}

Ширинкина Алиса Сергеевна, младший научный сотрудник, Пермский федеральный исследовательский центр УрО РАН (ПФИЦ УрО РАН), 614900, г. Пермь, ул. Ленина, 13А; e-mail: ali.shirinkina@mail.ru

Максимов Александр Юрьевич, кандидат биологических наук, доцент кафедры микробиологии и иммунологии, Институт экологии и генетики микроорганизмов УрО РАН - филиал Пермского федерального исследовательского центра УрО РАН (ИЭГМ УрО РАН), 614081, г. Пермь, ул. Голева, 13; e-mail: almaks1@mail.ru 